\title{
Type D Personality is Associated With Disease Severity and Poor Quality of Life in Turkish Patients With Fibromyalgia Syndrome: A Cross-Sectional Study
}

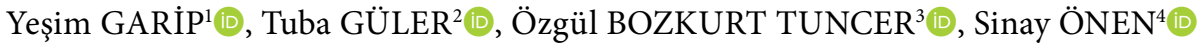 \\ ${ }^{1}$ Department of Physical Medicine and Rehabilitation, Ankara Numune Training and Research Hospital, Ankara, Turkey \\ ${ }^{2}$ Department of Physical Medicine and Rehabilitation, Derince Training and Research Hospital, Kocaeli, Turkey \\ ${ }^{3}$ Department of Physical Medicine and Rehabilitation, Medipol University Medical School, Istanbul, Turkey \\ ${ }^{4}$ Department of Psychiatry, Şevket Yilmaz Training and Research Hospital, Bursa, Turkey
}

\begin{abstract}
Objectives: This study aims to investigate the rate of type D personality in Turkish patients with fibromyalgia (FM) and evaluate its associations with clinical parameters of FM as well as its effects on health-related quality of life (HRQoL).

Patients and methods: The study included 100 patients with FM (14 males, 86 females; mean age $34.6 \pm 7.4$ years; range, 22 to 49 years) fulfilling 1990 American College of Rheumatology diagnostic criteria and 50 healthy controls ( 9 males, 41 females; mean age $32.6 \pm 6.5$ years; range, 21 to 50 years). Type D personality was assessed using the type D scale-14 (DS-14). FM disease severity was determined by Fibromyalgia Impact Questionnaire (FIQ), functional status by Stanford Health Assessment Questionnaire (HAQ), and HRQoL by Nottingham Health Profile (NHP). Severity of pain and fatigue were measured by visual analog scale (VAS).

Results: The frequency of type D personality was 33\% in FM patients and $12 \%$ in controls (odds ratio $=3.612,95 \%$ confidence interval $1.398-9.333$ ) $(p=0.006)$. Type D FM patients scored higher in tender point count (TPC), FIQ, HAQ, VAS-pain and all NHP subgroups except energy ( $p<0.01)$. Type D personality was found to be correlated with FIQ, TPC, HAQ, VAS-pain and NHP subgroups except energy $(p<0.01)$.

Conclusion: Based on our findings, assessment of personality characteristics of patients with FM may hold the key for the treatment of the disease. Besides, a better understanding of personality-related pain in FM patients may provide a more targeted approach to pain treatment.

Keywords: Fibromyalgia, pain, personality, quality of life.
\end{abstract}

Fibromyalgia (FM) is a common disorder characterized by unexplained widespread pain associated with 'tender points' which tend to be painful to touch. ${ }^{1}$ Its pathogenesis has been thought as an altered processing of pain arising from neuroendocrine, neurotransmitter and sleep perturbation. ${ }^{2,3}$ Although the main symptom of FM is pain, patients may also experience additional symptoms such as fatigue, depression, sleep disorders, stiffness, headache, dizziness, muscle spasms and paresthesia. ${ }^{4,5}$ In epidemiological studies, the prevalence of FM in general population was reported to range from 7.3 to $12.9 \% .^{6}$ In previous researches, it has been found to be linked with various psychiatric disorders including depression, ${ }^{7,8}$ anxiety, ${ }^{9,10}$ post-traumatic stress disorder, ${ }^{11}$ alexithymia, ${ }^{12,13}$ panic disorder, ${ }^{14}$ migraine, ${ }^{15,16}$ restless leg syndrome $e^{17}$ and irritable bowel syndrome. ${ }^{18}$ Furthermore, psychological symptoms were

Received: December 05, 2018 Accepted: March 04, 2019 Published online: November 06, 2019

Correspondence: Yeşim Garip, MD. Ankara Numune Eğitim ve Araştırma Hastanesi Fiziksel Tıp ve Rehabilitasyon Kliniği, 06230 Altındağ, Ankara, Turkey. Tel: +90 312 - 2691717 e-mail: dryesimgarip@gmail.com 
found to be associated with disease severity, poor physical fitness and deterioration in quality of life $(\mathrm{QoL})$ in the patients with FM. ${ }^{19}$

Type $\mathrm{D}$ personality is a distressed personality type involving two personality traits, namely negative affectivity and social inhibition, which are described as tendency to experience negative emotions and to inhibit self-expression in social relationships, respectively. ${ }^{20}$ Individuals with negative affectivity commonly concentrate on negative aspects of life and are likely to experience negative feelings such as distress, dissatisfaction, irritability, anxiety and depression. ${ }^{21}$ Socially inhibited individuals tend to feel unsafe and vulnerable in social interactions. The prevalence of type $\mathrm{D}$ personality is $21 \%$ in the general population and increases in cardiovascular diseases such as coronary heart disease and hypertension. ${ }^{22}$ In previous studies, type $\mathrm{D}$ personality was reported to be associated with poor clinical outcomes in ischemic heart disease, ${ }^{23}$ cardiac arrhythmias, ${ }^{24}$ and peripheral arterial disease. ${ }^{25}$ Although there are sufficient numbers of studies focusing on the relationship between type $\mathrm{D}$ personality and cardiovascular diseases; few data are available on the role of type $\mathrm{D}$ personality on FM.

We hypothesized that FM might be associated with type $\mathrm{D}$ personality. we aimed to investigate the rate of type $\mathrm{D}$ personality in Turkish patients with FM and evaluate its associations with clinical parameters of FM as well as its effects on healthrelated quality of life (HRQoL).

\section{PATIENTS AND METHODS}

The study included 100 patients with FM

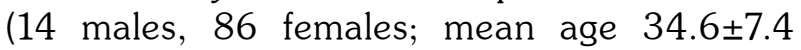
years; range, 22 to 49 years) applying to physical medicine and rehabilitation clinics of Derince Training and Research Hospital and Medipol University Esenler Hospital, between December 2015 and May 2016. FM was diagnosed based on 1990 American College of Rheumatology diagnostic criteria: ${ }^{26}$ (i) chronic pain which occurs on both sides of the body, both axial and peripheral, below and above the waist; (ii) minimum 11 of 18 tender points with digital palpation with an approximate force of $4 \mathrm{~kg} / \mathrm{cm}^{2}$. Tender point count (TPC) was measured by the same physician. Control group included 50 age and sex-matched healthy subjects (9 males, 41 females; mean age $32.6 \pm 6.5$ years; range, 21 to 50 years). Exclusion criteria for both patients and controls were inflammatory rheumatic diseases such as rheumatoid arthritis, ankylosing spondylitis, Sjögren's syndrome; endocrine diseases such as diabetes mellitus, thyroid and parathyroid disorders, and malignancies. Disease severity was determined by Fibromyalgia Impact Questionnaire (FIQ). ${ }^{27}$ Functional status was evaluated by Stanford Health Assessment Questionnaire (HAQ), ${ }^{28}$ and HRQoL by Nottingham Health Profile (NHP). ${ }^{29}$ Severity of pain and fatigue was measured by using $10-\mathrm{cm}$ visual analog scale (VAS). ${ }^{30}$

Type D personality was assessed by a psychiatrist using the Turkish version of type D scale-14 (DS-14). ${ }^{31}$ DS-14 (Figure 1) was developed in 2005 by Denollet ${ }^{22}$ as a measure of negative affectivity and social inhibition in order to be used in epidemiologic and clinical studies. It includes two subscales which assess negative affectivity and social inhibition. Each subscale consists of seven items and each item is scored between 0 and 4 . Scores $\geq 10$ in negative affectivity and social inhibition subscales indicate type $\mathrm{D}$ personality. FM patients were divided into two groups as type $\mathrm{D}$ and non-type $\mathrm{D}$ patients.

The study protocol was approved by the Kocaeli University Medical School Ethics Committee. A written informed consent was obtained from each participant. The study was conducted in accordance with the principles of the Declaration of Helsinki.

\section{Statistical analysis}

Statistical analyses were carried out using IBM SPSS for Windows, version 21.0 (IBM Inc., Armonk, NY, USA). Descriptive statistics (mean, median, standard deviation, minimum, maximum and frequencies) were used for assessing the demographics and clinical parameters. Differences among groups were evaluated by using independent samples t-test. Chi-square test was used to compare groups of categorical variables. The presence of correlation was determined by Pearson's correlation 


\begin{tabular}{|c|c|c|}
\hline $\begin{array}{l}\text { Below a } \\
\text { appropri } \\
\text { is the on }\end{array}$ & $\begin{array}{l}\text { number of statements that people often use to describe ther } \\
\text { number next to the statement to indicate your answer. There } \\
\text { ing that matters. }\end{array}$ & $\begin{array}{l}\text { then ci } \\
\text { own imp }\end{array}$ \\
\hline 0: False & ather false 2: Neutral 3: Rather true 4: True & \\
\hline 1 & I make contact easily when I meet people & 01234 \\
\hline 2 & I often make a fuss about unimportant things & 01234 \\
\hline 3 & I often talk to strangers & 01234 \\
\hline 4 & I often feel unhappy & 01234 \\
\hline 5 & I am often irritated & 01234 \\
\hline 6 & I often feel inhibited in social interactions & 01234 \\
\hline 7 & I take a gloomy view of things & 01234 \\
\hline 8 & I find it hard to start a conversation & 01234 \\
\hline 9 & I am often in a bad mood & 01234 \\
\hline 10 & I am a closed kind of person & 01234 \\
\hline 11 & I would rather keep other people at a distance & 01234 \\
\hline 12 & I often find myself worrying about something & 01234 \\
\hline 13 & I am often down in the dumps & 01234 \\
\hline 14 & When socializing, I don't find the right things to talk about & 01234 \\
\hline
\end{tabular}

Figure 1. Type D Scale-14 (DS-14).

coefficient. $\mathrm{P}$ values $<0.01$ were considered statistically significant.

\section{RESULTS}

Age did not significantly differ between FM patients and healthy controls $(p=0.096)$. Demographic and clinical patient data are given in Table 1. According to DS-14, the frequency of type D personality was $33 \%$ in FM patients and $12 \%$ in healthy controls (odds ratio $=3.612$, $95 \%$ confidence interval 1.398-9.333) $(\mathrm{p}=0.006)$ (Table 2).

A comparison of type D $(n=33)$ and nontype D FM patients $(n=67)$ showed that type D FM patients scored significantly higher in TPC, FIQ, HAQ, VAS-pain, and all NHP subgroups except energy $(p<0.01)$. There was no statistically significant difference in VAS-fatigue among groups ( $p>0.01$ ) (Table 3).

Negative affectivity and social inhibition were found to be significantly correlated with TPC, FIQ, HAQ, VAS-pain and all NHP subgroups except energy $(p<0.01)$. When the correlation coefficients were analyzed, both negative affectivity and social inhibition showed the highest correlation with VAS-pain. There was no statistically significant correlation between negative affectivity and social inhibition and VAS-fatigue ( $\mathrm{p}>0.01)$ (Table 4).

Table 1. Demographic and clinical patient data

\begin{tabular}{lcc}
\hline & Mean \pm SD & Min-Max \\
\hline Age (year) & $34.6 \pm 7.4$ & $22-49$ \\
Pain (VAS, $10 \mathrm{~cm}$ ) & $6.7 \pm 1.7$ & $4-10$ \\
Fatigue (VAS, $10 \mathrm{~cm})$ & $4.2 \pm 3.4$ & $0-10$ \\
Tender point count & $13.8 \pm 2.4$ & $11-18$ \\
FIQ & $71.4 \pm 14.9$ & $43-100$ \\
HAQ & $0.8 \pm 0.7$ & $0-3$ \\
NHP-pain & $72.5 \pm 17.5$ & $25-100$ \\
NHP-physical mobility & $32.8 \pm 24.5$ & $0-75$ \\
NHP-energy & $40.0 \pm 41.4$ & $0-100$ \\
NHP-sleep & $64.1 \pm 24.2$ & $0-100$ \\
NHP-social isolation & $30.4 \pm 36.3$ & $0-100$ \\
NHP-emotional reactions & $61.9 \pm 27.2$ & $0-100$ \\
\hline SD: Standard deviation; Min: Minimum; Max: Maximum; VAS: Visual \\
analog scale; FIQ: Fibromyalgia Impact Questionnaire; HAQ: Stanford \\
Health Assessment Questionnaire; NHP: Nottingham Health Profile. \\
\hline
\end{tabular}


Table 2. Prevalence of type D personality in fibromyalgia patients and controls

\begin{tabular}{lccccc}
\hline & $\mathrm{n}$ & $\%$ & Difference & $95 \%$ CI & $p$ \\
\hline Fibromyalgia patients $(\mathrm{n}=100)$ & 33 & 33 & 3.612 & $1.4-9.3$ & $0.006^{*}$ \\
Healthy controls $(\mathrm{n}=50)$ & 6 & 12 & & & \\
\hline CI: Confidence interval; ${ }^{*} \mathrm{p}<0.01$ was considered statistically significant. & & & & \\
\hline
\end{tabular}

Table 3. Comparison of clinical variables and HRQoL between type $\mathrm{D}$ and non-type $\mathrm{D}$ fibromyalgia patients

\begin{tabular}{|c|c|c|c|}
\hline & Type D FM patients $(\mathrm{n}=33)$ & Non-type D FM patients $(\mathrm{n}=67)$ & \\
\hline & Mean \pm SD & Mean \pm SD & $p$ \\
\hline Pain (VAS, $10 \mathrm{~cm}$ ) & $8.6 \pm 0.8$ & $5.8 \pm 1.2$ & $<0.00001^{*}$ \\
\hline Fatigue (VAS, $10 \mathrm{~cm}$ ) & $4.5 \pm 3.2$ & $4.0 \pm 3.5$ & 0.6 \\
\hline Tender point count & $15.7 \pm 2.3$ & $12.9 \pm 1.9$ & $<0.00001^{*}$ \\
\hline Fibromyalgia impact questionnaire & $86.3 \pm 8.4$ & $64.1 \pm 11.4$ & $<0.00001^{*}$ \\
\hline Stanford health assessment questionnaire & $1.2 \pm 0.8$ & $0.5 \pm 0.5$ & $<0.00001^{*}$ \\
\hline NHP-pain & $89.2 \pm 10.7$ & $64.3 \pm 14.1$ & $<0.00001^{*}$ \\
\hline NHP-physical mobility & $53.4 \pm 16.9$ & $22.6 \pm 21.0$ & $<0.00001^{*}$ \\
\hline NHP-energy & $45.5 \pm 42.1$ & $37.3 \pm 41.1$ & 0.358 \\
\hline NHP-sleep & $80.0 \pm 19.4$ & $56.2 \pm 22.6$ & $<0.00001^{*}$ \\
\hline NHP-social isolation & $60.6 \pm 37.2$ & $15.5 \pm 25.1$ & $<0.00001^{*}$ \\
\hline NHP-emotional reactions & $83.7 \pm 14.1$ & $51.5 \pm 25.1$ & $<0.00001^{*}$ \\
\hline
\end{tabular}

Table 4. Correlation of type DS-14 components with clinical parameters and HRQoL

\begin{tabular}{|c|c|c|c|}
\hline & & Negative affectivity & Social inhibition \\
\hline \multirow{2}{*}{ Pain (VAS, $10 \mathrm{~cm}$ ) } & $\mathrm{r}$ & 0.801 & 0.777 \\
\hline & $\mathrm{p}$ & $<0.00001^{*}$ & $<0.00001^{*}$ \\
\hline \multirow{2}{*}{ Fatigue (VAS, $10 \mathrm{~cm}$ ) } & $\mathrm{r}$ & 0.138 & 0.071 \\
\hline & $\mathrm{p}$ & 0.170 & 0.483 \\
\hline \multirow{2}{*}{ Tender point count } & $\mathrm{r}$ & 0.624 & 0.555 \\
\hline & $\mathrm{p}$ & $<0.00001^{*}$ & $<0.00001^{*}$ \\
\hline \multirow{2}{*}{ Fibromyalgia impact questionnaire } & $\mathrm{r}$ & 0.758 & 0.703 \\
\hline & $\mathrm{p}$ & $<0.00001^{*}$ & $<0.00001^{*}$ \\
\hline \multirow{2}{*}{ Stanford health assessment questionnaire } & $\mathrm{r}$ & 0.615 & $<0.00001^{*}$ \\
\hline & $\mathrm{p}$ & 0.626 & $<0.00001^{*}$ \\
\hline \multirow{2}{*}{ NHP-pain } & $\mathrm{r}$ & 0.691 & 0.676 \\
\hline & $\mathrm{p}$ & $<0.00001^{*}$ & $<0.00001^{*}$ \\
\hline \multirow{2}{*}{ NHP-physical mobility } & $\mathrm{r}$ & 0.667 & 0.554 \\
\hline & $\mathrm{p}$ & $<0.00001^{*}$ & $<0.00001^{*}$ \\
\hline \multirow{2}{*}{ NHP-energy } & $\mathrm{r}$ & 0.151 & 0.128 \\
\hline & $\mathrm{p}$ & 0.135 & 0.205 \\
\hline \multirow{2}{*}{ NHP-sleep } & $\mathrm{r}$ & 0.470 & 0.494 \\
\hline & $\mathrm{p}$ & $<0.00001^{*}$ & $<0.00001^{*}$ \\
\hline \multirow{2}{*}{ NHP-social isolation } & $\mathrm{r}$ & 0.533 & 0.692 \\
\hline & $\mathrm{p}$ & $<0.00001^{*}$ & $<0.00001^{*}$ \\
\hline \multirow{2}{*}{ NHP-emotional reactions } & $\mathrm{r}$ & 0.684 & 0.568 \\
\hline & $\mathrm{p}$ & $<0.00001^{*}$ & $<0.00001^{*}$ \\
\hline
\end{tabular}




\section{DISCUSSION}

Type $\mathrm{D}$ personality is based on two stable personality traits: negative affectivity and social inhibition. ${ }^{20}$ Previous studies have suggested that patients with FM have negative affectivity ${ }^{32}$ and poor social QoL. ${ }^{33}$ However, to our knowledge, there are only two studies in the literature examining the frequency of type $\mathrm{D}$ personality in patients with FM. In a 559-case cross-sectional study from Netherlands, the prevalence of type D personality in patients with FM was reported to be 56\%. ${ }^{34}$ In another study performed in Israel, 30\% of FM patients were found to have type D personality. ${ }^{35}$ In the present study, 33\% of FM patients were found to have Type D personality; this rate was significantly higher than that of healthy controls (12\%). In previous studies, the frequency of type $\mathrm{D}$ personality construct in Turkey was described as follows: $27.7 \%$ in hemodialysis patients ${ }^{31}$ and $56.8 \%$ in patients with multiple sclerosis. ${ }^{36}$ Our study has demonstrated that type $\mathrm{D}$ personality trait is common among Turkish patients with FM. To the best of our knowledge, this is the first study to report the rate of type $\mathrm{D}$ personality in Turkish FM patients.

In our study, type D FM patients showed poorer HRQoL in terms of pain, physical mobility, sleep, and social and emotional functions and more impairment in functional status compared to non-type D FM patients. Moreover, negative affectivity and social inhibition were found to be correlated with HAQ and all HRQoL domains except energy in FM patients. Similarly, in a study of van Middendorp et al., ${ }^{34}$ type D personality was reported to be associated with worse mental health and poor QoL regarding social and emotional functioning. Additional studies have also confirmed the negative impact of type $\mathrm{D}$ personality on HRQoL in other diseases. In a study of Mols and Denollet ${ }^{37}$ conducted on patients with chronic pain, chronic lung diseases, sleep disorders, traumatic brain injury, vertigo, melanoma and diabetic ulcers, a significant relationship was found between type $\mathrm{D}$ personality and poor physical and mental health status. Moreover, Schiffer et al. ${ }^{38}$ conducted a prospective study on patients with chronic heart failure to investigate the impact of type $\mathrm{D}$ personality and its stability over time on health status. They found more improvement in health status over time in non-type $\mathrm{D}$ patients as compared to type $\mathrm{D}$ patients. On the other hand, Erkol Inal et al. ${ }^{39}$ reported an association between type $\mathrm{D}$ personality trait and mental domains of HRQoL in Turkish patients with ankylosing spondylitis.

In the present study, FM patients with this type of personality showed higher disease severity compared to non-type D subjects. Moreover, negative affectivity and social inhibition were found to be correlated with FIQ and TPC levels. To the best of our knowledge, this study is the first to demonstrate an association between type $\mathrm{D}$ personality and disease severity in the patients with FM. Possible mechanisms that may explain poor clinical outcomes in type D FM patients include dysregulation of hypothalamic-pituitaryadrenal axis, ${ }^{40}$ tumor necrosis factor-alpha $\left(\right.$ TNF- $\alpha$ ) dysregulation ${ }^{41}$ and increased oxidative stress in cardiac diseases. ${ }^{23}$ Since elevated levels of TNF- $\alpha,{ }^{42}$ hypothalamic-pituitary-adrenal axis disturbances, ${ }^{43}$ and oxidative stress ${ }^{44}$ also play a role in the onset and continuation of FM; these pathways may also explain the relationship between type $\mathrm{D}$ personality and disease severity in the patients with FM. Besides, non-adherence to medication and reluctance to contact a healthcare provider may be additional factors in this relation. ${ }^{40}$

In the current study, VAS-pain scores of FM patients with type $\mathrm{D}$ personality were higher than those of non-type D patients. Additionally, negative affectivity and social inhibition showed the strongest correlation with pain severity among clinical parameters. The relationship between negative affectivity and pain is explained by psychological aspects of pain perception. ${ }^{45}$ Emotional factors modulate pain perception via various pathways including projections from the midbrain periaqueductal grey to brainstem nuclei, including the rostroventral medulla and locus coeruleus, to the dorsal horn of the spinal cord. These tracts comprehend opioids, norepinephrine and serotonin, and have inhibitory and excitatory effects on medulla spinalis afferent projection neurons. Outputs from anterior cingulate cortex, prefrontal cortex, and amygdala reach periaqueductal grey, indicating that these descending systems might be stimulated by emotional factors. ${ }^{45}$ Further studies conducted 
on patients with other chronic pain syndromes are required to elucidate the relationship between type $\mathrm{D}$ personality and pain.

We found no difference in VAS-fatigue and NHP-energy scores of type D and non-type D patients with FM. Also, no significant correlation existed between VAS-fatigue and negative affectivity or social inhibition. These findings indicate that type $\mathrm{D}$ personality components, namely negative affectivity and social inhibition, are mainly linked with pain, but not fatigue symptoms in patients with FM.

This study has two limitations. First is the relatively small study sample, while second is the cross sectional design of the study which is inadequate to reflect the changes in parameters and to detect cause-and-effect relationships.

In conclusion, type $\mathrm{D}$ personality is prevalent among Turkish patients with FM, with a rate of $33 \%$. It is associated with poor HRQoL regarding pain, physical mobility, sleep, and social and emotional functions. Presence of type $\mathrm{D}$ personality should be taken into account in FM to develop new treatment strategies for patients who have inadequate response to conventional therapies. In case of type $\mathrm{D}$ personality in a FM patient, we should be in collaboration with a psychiatrist. Besides medical therapy, group therapies including both cognitive-behavioral approaches and exercises may be considered in this process.

\section{Declaration of conflicting interests}

The authors declared no conflicts of interest with respect to the authorship and/or publication of this article.

\section{Funding}

The authors received no financial support for the research and/or authorship of this article.

\section{REFERENCES}

1. Hudson JI, Goldenberg DL, Pope HG Jr, Keck PE Jr, Schlesinger L. Comorbidity of fibromyalgia with medical and psychiatric disorders. Am J Med 1992;92:363-7.

2. Perrot S, Winkelmann A, Dukes E, Xu X, Schaefer $\mathrm{C}$, Ryan $\mathrm{K}$, et al. Characteristics of patients with fibromyalgia in France and Germany. Int $\mathrm{J}$ Clin Pract 2010;64:1100-8.
3. Tomasevic-Todorovic S, Pjevic M, Boskovic K. Fibromyalgia-up to date aspects of pathophysiology diagnosis and treatment. Med Pregl 2010;63:507-11. [Abstract]

4. Martinez JE, Casagrande Pde M, Ferreira PP, Rossatto BL. Correlation between demographic and clinical variables and fibromyalgia severity. Rev Bras Reumatol 2013;53:460-3.

5. Jones CJ, Rutledge DN, Aquino J. Predictors of physical performance and functional ability in people $50+$ with and without fibromyalgia. J Aging Phys Act 2010;18:353-68.

6. Neumann L, Buskila D. Epidemiology of fibromyalgia. Curr Pain Headache Rep 2003;7:362-8.

7. Offenbaecher M, Glatzeder K, Ackenheil M. Selfreported depression, familial history of depression and fibromyalgia $(\mathrm{FM})$, and psychological distress in patients with FM. Z Rheumatol 1998;57:94-6.

8. Chang MH, Hsu JW, Huang KL, Su TP, Bai YM, $\mathrm{Li} \mathrm{CT}$, et al. Bidirectional Association Between Depression and Fibromyalgia Syndrome: A Nationwide Longitudinal Study. J Pain 2015;16:895-902.

9. Janssens KA, Zijlema WL, Joustra ML, Rosmalen JG. Mood and Anxiety Disorders in Chronic Fatigue Syndrome, Fibromyalgia, and Irritable Bowel Syndrome: Results From the LifeLines Cohort Study. Psychosom Med 2015;77:449-57.

10. Thieme K, Turk DC, Flor H. Comorbid depression and anxiety in fibromyalgia syndrome: relationship to somatic and psychosocial variables. Psychosom Med 2004;66:837-44

11. Cohen H, Neumann L, Haiman Y, Matar MA, Press J, Buskila D. Prevalence of post-traumatic stress disorder in fibromyalgia patients: overlapping syndromes or post-traumatic fibromyalgia syndrome? Semin Arthritis Rheum 2002;32:38-50.

12. AvilaLA, de Araujo Filho GM, Guimarães EF, Gonçalves LC, Paschoalin PN, Aleixo FB. Characterization of the pain, sleep and alexithymia patterns of patients with fibromyalgia treated in a Brazilian tertiary center. Rev Bras Reumatol 2014;54:409-13. [Abstract]

13. Castelli L, Tesio V, Colonna F, Molinaro S, Leombruni P, Bruzzone M, et al. Alexithymia and psychological distress in fibromyalgia: prevalence and relation with quality of life. Clin Exp Rheumatol 2012;30:70-7.

14. Malt EA, Berle JE, Olafsson S, Lund A, Ursin H. Fibromyalgia is associated with panic disorder and functional dyspepsia with mood disorders. A study of women with random sample population controls. J Psychosom Res 2000;49:285-9.

15. Vij B, Whipple MO, Tepper SJ, Mohabbat AB, Stillman M, Vincent A. Frequency of Migraine Headaches in Patients With Fibromyalgia. Headache 2015;55:860-5.

16. Marcus DA, Bhowmick A. Fibromyalgia comorbidity in a community sample of adults with migraine. Clin Rheumatol 2013;32:1553-6. 
17. Yunus MB, Aldag JC. Restless legs syndrome and leg cramps in fibromyalgia syndrome: a controlled study. BMJ 1996;312:1339.

18. Sivri A, Cindaş A, Dinçer F, Sivri B. Bowel dysfunction and irritable bowel syndrome in fibromyalgia patients. Clin Rheumatol 1996;15:283-6.

19. Del Pozo-Cruz J, Alfonso-Rosa RM, Castillo-Cuerva A, Sañudo B, Nolan P, Del Pozo-Cruz B. Depression symptoms are associated with key health outcomes in women with fibromyalgia: a cross-sectional study. Int $\mathrm{J}$ Rheum Dis 2017;20:798-808.

20. Denollet J. Type D personality. A potential risk factor refined. J Psychosom Res 2000;49:255-66.

21. Mikkelsen EG, Einarsen S. Relationships between exposure to bullying at work and psychological and psychosomatic health complaints: the role of state negative affectivity and generalized self-efficacy. Scand J Psychol 2002;43:397-405.

22. Denollet J. DS14: standard assessment of negative affectivity, social inhibition, and Type D personality. Psychosom Med 2005;67:89-97.

23. Kupper N, Gidron Y, Winter J, Denollet J. Association between type $\mathrm{D}$ personality, depression, and oxidative stress in patients with chronic heart failure. Psychosom Med 2009;71:973-80.

24. Denollet J, Tekle FB, van der Voort PH, Alings M, van den Broek KC. Age-related differences in the effect of psychological distress on mortality: Type $\mathrm{D}$ personality in younger versus older patients with cardiac arrhythmias. Biomed Res Int 2013;2013:246035.

25. Aquarius AE, Denollet J, de Vries J, Hamming JF. Poor health-related quality of life in patients with peripheral arterial disease: type D personality and severity of peripheral arterial disease as independent predictors. J Vasc Surg 2007;46:507-12.

26. Wolfe F, Smythe HA, Yunus MB, Bennett RM, Bombardier C, Goldenberg DL, et al. The American College of Rheumatology 1990 Criteria for the Classification of Fibromyalgia. Report of the Multicenter Criteria Committee. Arthritis Rheum 1990;33:160-72.

27. Sarmer S, Ergin S, Yavuzer G. The validity and reliability of the Turkish version of the Fibromyalgia Impact Questionnaire. Rheumatol Int 2000;20:9-12.

28. Küçükdeveci AA, Sahin H, Ataman S, Griffiths B, Tennant A. Issues in cross-cultural validity: example from the adaptation, reliability, and validity testing of a Turkish version of the Stanford Health Assessment Questionnaire. Arthritis Rheum 2004;51:14-9.

29. Kücükdeveci AA, McKenna SP, Kutlay S, Gürsel $\mathrm{Y}$, Whalley $\mathrm{D}$, Arasil $\mathrm{T}$. The development and psychometric assessment of the Turkish version of the Nottingham Health Profile. Int $\mathrm{J}$ Rehabil Res 2000;23:31-8.

30. Price DD, McGrath PA, Rafii A, Buckingham B. The validation of visual analogue scales as ratio scale measures for chronic and experimental pain. Pain 1983;17:45-56.
31. Alçelik A, Ylldırım O, Canan F, Eroğlu M, Aktaş G, Şavlı H. Preliminary psychometric evaluation of the type D personality construct in Turkish hemodialysis patients. J Mood Dis 2012;2:1-5.

32. Staud R, Robinson ME, Vierck CJ Jr, Cannon RC, Mauderli AP, Price DD. Ratings of experimental pain and pain-related negative affect predict clinical pain in patients with fibromyalgia syndrome. Pain 2003;105:215-22.

33. Verbunt JA, Pernot DH, Smeets RJ. Disability and quality of life in patients with fibromyalgia. Health Qual Life Outcomes 2008;6:8.

34. van Middendorp H, Kool MB, van Beugen S, Denollet $\mathrm{J}$, Lumley MA, Geenen R. Prevalence and relevance of Type D personality in fibromyalgia. Gen Hosp Psychiatry 2016;39:66-72.

35. Ablin JN, Zohar AH, Zaraya-Blum R, Buskila D. Distinctive personality profiles of fibromyalgia and chronic fatigue syndrome patients. PeerJ 2016;4:e2421.

36. Demirci S, Demirci K, Demirci S. The effect of type d personality on quality of life in patients with multiple sclerosis. Noro Psikiyatr Ars 2017;54:272-6.

37. Mols F, Denollet J. Type D personality among noncardiovascular patient populations: a systematic review. Gen Hosp Psychiatry 2010;32:66-72.

38. Schiffer AA, Pedersen SS, Widdershoven JW, Denollet J. Type D personality and depressive symptoms are independent predictors of impaired health status in chronic heart failure. Eur J Heart Fail 2008;10:802-10.

39. Erkol İnal E, Demirci K, Doğru A, Şahin M. Ankylosing Spondylitis patients with Type D personality have worse clinical status. Mod Rheumatol 2016;26:138-45.

40. Denollet J, Conraads VM. Type D personality and vulnerability to adverse outcomes in heart disease. Cleve Clin J Med 2011;78:13-9.

41. Denollet J, Vrints CJ, Conraads VM. Comparing Type $\mathrm{D}$ personality and older age as correlates of tumor necrosis factor-alpha dysregulation in chronic heart failure. Brain Behav Immun 2008;22:736-43.

42. Ablin J, Neumann L, Buskila D. Pathogenesis of fibromyalgia - a review.Joint Bone Spine 2008;75:273-9.

43. Crofford LJ, Pillemer SR, Kalogeras KT, Cash JM, Michelson D, Kling MA, et al. Hypothalamicpituitary-adrenal axis perturbations in patients with fibromyalgia. Arthritis Rheum 1994;37:1583-92.

44. Romano GF, Tomassi S, Russell A, Mondelli V, Pariante CM. Fibromyalgia and chronic fatigue: the underlying biology and related theoretical issues. Adv Psychosom Med 2015;34:61-77.

45. Bushnell MC, Ceko M, Low LA. Cognitive and emotional control of pain and its disruption in chronic pain. Nat Rev Neurosci 2013;14:502-11. 